\title{
¿Por qué es un error enseñar la cultura y la interculturalidad?
}

\author{
José Sánchez-Parga*
}

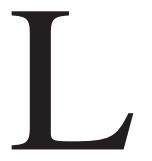

a problemática aquí planteada ha sido resultado de tres convergencias: a) una investigación anterior

(Crisis en torno al Quilotoa. Comunidad, Mujer y cultura), que descubre cómo los cambios culturales en un medio indígena, muy trabajado por programas de educación intercultural bilingüe, son vividos o bien como traiciones contra el pasado y sus tradiciones o como fugas hacia el futuro; b) un estudio reciente sobre los programas de educación intercultural bilingüe y su aplicación durante más de dos décadas en la región del Cotopaxi; c) un estudio en curso sobre el culturalismo en la sociedad actual, y cómo las hipertrofias culturalistas y de lo cultural tratan de encubrir y sustituir las atrofías y destrucción de lo social, en base a una versión positivista e instrumentalista de la cultura.

Cuando se depura la bibliografía existente y se procesan los cuestionarios sobre la educación intercultural, dos ideas se confirman con recurrencia: la opinión generalizada de que la interculturalidad es la relación o intercambio entre (dos) culturas, y que la cultura se enseña con la finalidad de reforzar la propia identidad cultural de un pueblo. Ahora bien, ambas ideas sobre cultura e interculturalidad no solo se han elaborado y difundido sobre falsos presupuestos, sino que además responden a una ideología culturalista, que tiende a encubrir los reales procesos socio-culturales

* Docente de la Universidad Politécnica Salesiana, investigador del Centro Andino de Acción Popular (CAAP), Quito. 
en la sociedad y mundo modernos. Y finalmente, lo que es peor, ambas ideas se contradicen, en la medida que un reforzamiento de la propia identidad cultural impediría los reales procesos de interculturalidad; sobre todo porque tal planteamiento no reconoce, que la propia identidad cultural es ya en sí misma producto de interacciones culturales.

De otro lado, el proyecto de educación intercultural, muy masivamente, se encuentra diseñado y orientado para su implementación en sectores indígenas, como si el fenómeno y la problemática culturalista no afectaran a toda la sociedad actual en su conjunto. De hecho, uno de los programas de educación intercultural bilingüe en Ecuador precisa sus objetivos en este sentido: que el indígena conozca muy bien su cultura y refuerce su identidad cultural, para poder participar en una relación de interculturalidad con la otra cultura, sin que ello afecte su identificación con la propia ${ }^{1}$. Como si el re-conocimiento de las otras culturas pudiera impedir o perturbar el reconocimiento de la propia acultura; cuando de hecho ocurre todo lo contrario: cuanto más se reconocen las otras culturas mejor es el reconocimiento de la propia.

Un mismo supuesto opera bajo tales posiciones ideológicas: que la cultura pudiera perderse precisamente al interior de un intercambio cultural y que uno de los factores que mejor reforzarían la identidad cultural es la conservación de la lengua. Tal identificación entre lengua y cultura ha dado lugar a que algunos indigenistas lleguen a hablar de la cultura quichua, ignorando que los procesos culturales y lingüísticos, aunque pueden y suelen estar relacionados, son diferentes e independientes, presentando sus relaciones morfológicas muy diferentes según los casos.

De hecho en los Andes septentrionales (del Ecuador) el quichua se impuso a los diferentes pueblos y grupos cul-

\footnotetext{
${ }^{1}$ Cfr. SÁNCHEZ PARGA, José. Educación Indígena en Cotopaxi. Avances políticos y deudas pedagógicas, CAAP, Quito, 2005.
} 
turales bajo la dominación inca pocos años antes de la llegada de los españoles y sería la posterior evangelización, ya bajo el dominio colonial, la que afirmaría y difundiría el uso del quichua, haciendo que terminaran "perdiéndose" las otras lenguas más originarias. Pero en ninguno de estos períodos de la historia "se perdió" la cultura ni siquiera las diferencias culturales de las poblaciones andinas.

\section{Las culturas no "se pierden" y nada se "pierde" de ellas}

Este mismo caso histórico sirve para despejar además uno de los equívocos culturales más generalizados, relativo a la idea de "pérdida" de la cultura y de la identidad cultural. En primer lugar, el cambio cultural no debe entenderse, como si se tratara de una pérdida de la propia cultura y de una adopción de otra cultura si no extraña al menos ajena. Lo que siempre ocurre es todo lo contrario, pues se trata además de un principio cultural: es porque se adopta otra lengua y se adopta otra cultura o rasgos culturales, que tiene lugar el decline y abandono de lo que se consideraba como la propia cultura. Es por consiguiente el proceso de una nueva identificación cultural, el que puede generar desidentificaciones y el abandono de otras identificaciones precedentes.

En segundo lugar, nunca hay una "pérdida" ni siquiera la sustitución de una cultura por otra o de un rasgo cultural por otro, e incluso en los grandes cambios y transformaciones culturales las duraciones, las prolongaciones y las continuidades no solo son más fuertes y consistentes que las adquisiciones y las innovaciones, sino que además son las que informan culturalmente estas y las envisten de sentidos y significaciones culturales propios. En ningún caso, por consiguiente, cabe pensar en abandonos ni pérdidas. Podríamos hablar de un "olvido", que transforma la cultura en una dimensión diferente, haciendo de ella todo lo que se 
olvida cuando se convierte en parte integrante de una sociedad. Si pensamos la cultura en términos de capital, una cosa es el capital activo de la cultura, cuando por cultura se entienden los hechos y experiencias, las prácticas y los objetos y otra cosa es cuando la cultura se vuelve el capital pasivo de una sociedad: se trata de una dimensión de la cultura, que condiciona todo lo que la sociedad hace y vive culturalmente; es el capital cultural que incluso condiciona las innovaciones culturales y las nuevas identificaciones de dicha sociedad.

Un ejemplo histórico se muestra elocuente al respecto. La presencia de los incas en los Andes septentrionales (actual Ecuador), poco más de un siglo antes de la llegada de los españoles, supuso una progresiva quichuización, la cual se prolongaría y completaría posteriormente bajo el proceso evangelizador del régimen colonial. En este sentido dichos pueblos no "perdieron" sus lenguas aborígenes sino que por razones de distinto orden se identificaron con la lengua quichua y la adaptaron. Fue por consiguiente una apropiación lingüística con su efecto homogeneizador, lo que provocó el abandono u olvido de las lengua vernáculas. Lo que, por otro lado, demuestra que los procesos lingüísticos son diferentes de los culturales².

En el transcurso de la historia de un pueblo la cultura deja de ser los objetos y las prácticas de una sociedad, deja de estar fuera de ella y de ser algo externo y objetivo, para hacerse dentro de ella, para irse subjetivando y volverse interior a dicha sociedad; cuando la cultura deja de reducirse a hechos y objetos o prácticas para convertirse en aquello que produce, articula y organiza todos los sentidos

\footnotetext{
${ }^{2}$ Mientras que los cambios lingüísticos han respondido siempre en la historia a procesos o bien de homogeneización o bien de diferenciación, los (inter)cambios culturales tienen siempre el doble efecto de entropía (homogenizadora) y de negentropía (diferenciadora), según Lévi-Strauss.
} 
y significaciones de dichas prácticas, hechos y objetos; como diría Devereux "transformada en material o en estructura psíquica, en Super-ego, ideal del Yo en Yo -en algo aprendido, producido o construido internamente: está dentro". En definitiva, la cultura deja de ser representada (socialmente) en cuanto producto de la sociedad, para ser pensada y vivida (sociológicamente) como productora del sentido de una sociedad o grupo humano. En esta dimensión de la cultura, en la "interna experiencia de la cultura" (J. Henry) no se puede hablar de "pérdidas" ni de "abandonos" culturales: la sociedad "vive su cultura como algo profundamente interiorizado, algo que es parte de su estructura y economía psíquica"'.

Hay una constante acumulación de capital cultural o capitalización de la cultura a lo largo del pasado de toda sociedad, pueblo o grupo humanos, la cual va condicionando su desarrollo cultural en el transcurso de su futuro histórico. En este sentido cabe concebir la cultura de un pueblo como el inconsciente del individuo: es el pasado, que sin ser consciente actúa de manera constante en el transcurso de toda la vida, dando sentido de todos sus hechos y episodios, pero que en todo momento de ella puede volverse consciente.

Los cambios y las innovaciones culturales no solo son producto de interculturalidad, entre las nuevas adquisiciones o identificaciones culturales y el pasado o capital cultural de la sociedad, sino también son dichos cambios e innovaciones productores de interculturalidad. Por eso es tan necesario e importante que los cambios e innovaciones se realicen y sean vividos no como una nueva identificación o reconocimiento a costa de la desindentificación y desreconocimiento con el pasado cultural, sino más bien sobre

3 Georges Devereux, Essais d'ethnopsychiatrie générale, Gallimard, Paris, 1970; Jules Henry, "The Inner Experience of Culture", en Psychiatry, n. 14, 1951. 
un doble re-conocimiento e identificación. Se requiere tanto que la sociedad o grupo se reconozca en los cambios e innovaciones como que esa misma sociedad y pueblo, en su manera de cambiar e innovar culturalmente, lo haga desde su pasado cultural y no desde el rechazo o des-reconocimiento de dicho pasado. Solo de esta manera los cambios e innovaciones serán una real y auténtica apropiación cultural. Lo cual significa que un tal cambio e innovación no constituyen una mera adquisición de otra cultura o de otro rasgo cultural, sino una real producción y apropiación culturales significativamente diferentes. En otras palabras, toda "adquisición" cultural, en la medida que se realiza "interculturalmente", comporta siempre una real y propia producción de cultura; una innovación cultural. Y por esta precisa razón no hay propiamente culturas híbridas y sería un equívoco pensar las culturas en términos de hibridaciones. Ya que cada cultura, cada proceso e innovación culturales son siempre originales.

Pocos grupos étnicos en Ecuador han cambiado e innovado culturalmente como los otavaleños, e incluso dentro de Otavalo los indígenas de Peguche parecen haberse apropiado de los significantes más característicos de la modernidad (norteamericana); pero estos cambios han tenido lugar a partir del reconocimiento de la propia cultura, e invistiéndolos de diferencias muy significativas; ya que la supuesta "adquisición" de lo supuestamente "extranjero" no se realizó a partir de una des-identificación o des-re-conocimiento del propio pasado cultural. En tal sentido, toda "adopción" o "adaptación" responde interculturalmente a una real apropiación y producción culturales; es decir, a una verdadera innovación cultural.

Es obvio que si se reduce la cultura de una sociedad a sus hechos y prácticas, a sus objetos y experiencias, los cambios y las innovaciones culturales aparecen provocando "sustituciones" y "pérdidas" del pasado cultural de dicha 
sociedad; pero la cultura es también y sobre todo esa parte del "olvido" o ese pasado sumergido bajo la línea de flotación de la sociedad, que confiere sentido y significados culturales a todo lo que esa sociedad hace y produce. Sin esa comunicación o intercambio, interculturalidad, entre el pasado y presente, lo vivido y lo olvidado de la sociedad no hay cultura.

Por otro lado, en consecuencia, en lo que aparece como abandono o sustitución (pero no "pérdida") de una cultura considerada como "propia", hay que reconocer más bien que lo "propio" cultural ha sido siempre en algún momento de la historia objeto de una apropiación cultural, y que no habría cultura o rasgos culturales por más "extraños y ajenos" que parezcan, que no puedan ser apropiables por cualquier cultura, puesto que en definitiva todas las culturas no son más que variaciones de la misma cultura humana. Esto exactamente ha ocurrido con el quichua en los Andes septentrionales: objeto de una apropiación cultural, como resultado de un doble proceso histórico de dominación colonial incaico primero y de evangelización posterior bajo el dominio español ${ }^{4}$.

Todo lo cual significa también que nada cultural es tan propio que no pueda ser sustituido por rasgos de otra cultura, obligando siempre a considerar lo que en una cultura cambia y perdura; que en términos de cultura nada es tan exterior a una cultura que no sea interior a una área cultural común entre culturas, y por ello mismo que no pueda ser internalizado por un proceso de apropiación intercultural.

\footnotetext{
${ }^{4}$ Dos casos históricos muy representativos de las complejas relaciones entre lengua y cultura fueron el gran influjo cultural de la antigua Grecia sobre Roma, al mismo tiempo que la helenización lingüística del mundo mediterráneo cedía ante la latinización de todo el imperio romano; y posteriormente la invasión y dominación del vasto imperio romano por los pueblos góticos no impidió que el latín se impusiera a la cultura gótica y permaneciera lengua dominante.
} 
Estas precisiones permiten despejar otro equívoco muy generalizado en torno al concepto de a-culturación entendido de manera muy habitual como una pérdida cultural o de cultura al interior de un intercambio cultural, cuando en realidad significa todo lo contrario: el estado o proceso normal de toda cultura siempre referida y relativa u orientada a otras culturas y a sus intercambios . $^{5}$

Según esto nada impide que una sociedad, cualquier sociedad, pueda identificarse con una cultura, con uno u otro rasgo o conjunto cultural, con una u otra lengua. Todo lo contrario: es precisamente por su cultura que toda sociedad se encuentra abierta y predispuesta a las interacciones con otras sociedades, y más precisamente con la cultura de las otras_sociedades. Ahora bien, son siempre los cambios sociales, los que dan cuenta de los cambios culturales y no a la inversa. Siendo siempre lo cultural, que habrá de ser comprendido y explicado a partir de lo social. Y por consiguiente, también en este sentido sería aberrante pensar que es en razón de sus diferencias culturales, que los pueblos, sociedades y grupos humanos no pueden intercambiar y relacionarse entre sí; cuando de hecho ocurre todo lo contrario.

La relación entre una sociedad, un pueblo o grupo humano con su cultura nunca es esencial sino histórica; por ello ninguna forma o formación cultural determinada es necesaria a un pueblo, sociedad o grupo humano. Lo esencial y culturalmente necesario es que cada sociedad, cada pueblo y grupo humano se identifiquen siempre con un conjunto cultural que lo diferencia significativamente de otras

\footnotetext{
${ }^{5}$ El malentendido resulta de entender la A de a- culturación, como si se tratara del prefijo privativo o negativo latino, cuando por el contrario es el prefijo también latino $\mathrm{AD}$, que significa relación, referencia u orientación, lo que define el sentido del concepto de a-culturación.
} 
sociedades, pueblos y grupos humanos ${ }^{6}$. Considerando a la vez que no hay sociedad, pueblo o grupo humano que no comparta una masa más o menos grande de su cultura con otras sociedades o grupos humanos, al mismo tiempo que se diferencia significativamente de todos ellos ${ }^{7}$. Quizás no hay mejor ejemplo que la religión: si la experiencia y el hecho religioso es lo más universal y común a todas las sociedades a lo largo de la historia, por otro lado nada más diversificado y distinto y nada más cambiante y sujeto a transformaciones sociales a lo largo de la historia que los hechos y experiencias de la religión, incluso dentro de la misma tradición religiosa.

\section{¿Enseñar la cultura o más bien comprenderla y recono- cerse en la cultura?}

Cuando se estudian o analizan los programas de educación intercultural se constata que la materia o área de materias sobre la interculturalidad responden siempre a una suerte de antropología cultural vulgarizada, más o menos aplicada y simplificada. Lo que resultaría muy coherente con el presupuesto de dichos programas, según los cuales cuanto más y mejor se conoce la propia cultura tanto mejor

\footnotetext{
${ }^{6}$ El concepto de "diferencia significante" de Lévi-Strauss para definir la cultura ha de entenderse en un doble sentido: rasgos significativos que diferencian una sociedad o pueblo de otras socio-culturas, y que simultáneamente tienen toda su sentido en relación con todos los demás elementos y rasgos significativos de dicha cultura. En las culturas andinas las representaciones espaciales y de la organización social tienen correspondencias significativas no solo con las formas mentales de su concepción de la realidad sino también con su figurativa textil.

${ }^{7}$ Esto supone, en otras palabras, reconocer que el concepto de cultura es siempre analítico, puesto que la cultura, toda cultura, es siempre plural ("la cultura en plural" según M. de Certeau) así como sintético; ya que no hay diferencias culturales por muy significantes que parezcan que no compartan una misma área cultural.
} 
será la identificación con ella. Pero tal postulado recubre un doble cuestionamiento. En primer lugar, es epistemológicamente imposible e incluso un artificio epistemológico contraproducente el concebir una antropología de la propia cultura, puesto que la antropología es siempre un saber o discurso sobre el otro y desde el otro; por eso el programa antropológico comporta siempre un reconocimiento de la otra cultura desde sus diferencias significantes.

En consecuencia la propia cultura no puede conocerse (ser enseñada y aprendida) antropológicamente, o bien se conocería la propia cultura como si no fuera propia. Un tal enfoque hace de la antropología una ciencia social aplicada, restándole no solo competencias teóricas y analíticas, sino también (lo que resulta muy paradójico) la capacidad de aplicar sus conocimientos ${ }^{8}$.

Además de este argumento, habría que constatar que nunca antes en la historia la cultura ha sido objeto de enseñanza / aprendizaje, como si solo aprendida y enseñada pudiera ser la cultura adquirida: o lo que sería aun más absurdo: pensar que sin su enseñanza/aprendizaje los miembros de una sociedad no tendrían cultura o podrían quedarse sin ella.

Cuando en el fondo la cultura es una determinada forma de existir de toda sociedad, y una cualidad de la existencia de sus miembros.

En este sentido la cultura es tan "natural" (tan "cultural") como la lengua, pero lo que nunca es natural una u otra forma de cultura: los niños no nacen hablando, pero sí nacen sabiendo hablar; y aprenderán (naturalmente) a hablar cualquier lengua sin que nadie les enseñe ${ }^{9}$.

\footnotetext{
${ }^{8}$ Que las Ciencias Sociales no sean aplicadas en su modo de producir sus conocimientos, no impide que estos puedan ser aplicables. Cfr. J. Sánchez Parga, El oficio de antropólogo. Crítica de la razón (inter)cultural, Caap, Quito, 2005.

${ }^{9} \mathrm{Al}$ positivismo anglosajón de los orígenes de la moderna etnología debemos la idea de que la cultura es "todo lo adquirido" (Edward B. Taylor), como si el hecho de la adquisición y el mismo hombre que adquiere no fueran ya productos de cultura.
} 
Cuando Tucídides, en su oración fúnebre por los atenienses caídos en defensa de la ciudad, hace un elogio de la cultura de Atenas, destacando todas sus diferencias significativas respecto de otras sociedades, y dice que "toda la socio-cultura de la ciudad educa" (Historia, II, xli,1), no emplea ni el verbo enseñar (pedagogein) ni el verbo aprender (mathein), sino el verbo paidein, que debería traducirse por educar o más precisamente "socializar por la misma cultura". Es la intensa y estrecha convivencia en una sociedad y en sus instituciones con todos sus valores, lo que transmite y reproduce una cultura, pero también lo que la hace creativa y cambiante.

Solo cuando la cultura deja de ser pensada y vivida, no tanto como pertenencia sino como una dimensión a la que se pertenece, y de la que se participa en la medida que es compartida, solo entonces puede hacerse de ella el contenido de una enseñanza / aprendizaje; sólo cuando deja de ser una cualidad o forma de ser de una sociedad y de un pueblo, puede ser objetivada en cuanto contenido de una educación particular. Esto mismo implica ignorar que "no hay unidad cultural completa y que las culturas son construcciones que se transforman constantemente, reinterpretando nuevas experiencias, lo que vuelve artificial la búsqueda de una esencia... o también la reducción de una cultura a un código de conductas"10.

Pero esta necesidad de hacer de la cultura objeto de una particular educación responde además a una compulsión pedagogizante de la sociedad moderna, que pretende compensar con las enseñanzas los defectos y limitaciones de sus capacidades o competencias socializadoras. Por eso estos afanes o frenesís pedagógicos, lejos de limitarse a la cultura, se han extendido en la actualidad también a otros

${ }^{10}$ TOURAINE, Alain. ¿Pourrons - nous vivre ensemble? Egaux et Différents, Fayard, Paris, 1997: 205. 
ámbitos sociales, con la finalidad de compensar pedagógicamente los profundos déficits o crisis de su socialización. Por esta razón la sociedad moderna se ha puesto a "enseñar valores"; ya que una sociedad únicamente necesita enseñar lo que ella misma ya no valora; o cuando se ha quedado sin el principio o los criterios de "valorización racional" o "racionalización valorativa" (Max Weber).

El efecto más contraproducente y anti-intercultural de una enseñanza / aprendizaje de la cultura consiste en afirmar una fijación cultural, como si la cultura no cambiara y fuera una entidad a-histórica, y fijar una identidad cultural, que impidiera todas las posibles identificaciones culturales futuras. Más aún el hecho de participar en una misma cultura no excluye que esa misma cultura sea vivida e interpretada de manera diversa por todos quienes la comparten. Lo contrario supondría obligar a imponer dentro de la misma sociedad, pueblo o grupo humano una misma experiencia, versión y vivencia de la cultura. Por esta razón son insostenibles los llamados derechos culturales, ya que se convierten en obligaciones culturales, lo que supondría una absurda alienación cultural, en la medida que la cultura dejaría de ser producto de la libertad y libremente vivida ${ }^{11}$.

Así se muestra claramente cómo el error de la identidad cultural es análogo al de los derechos culturales en el mismo doble sentido: a) hace que hacia las otras culturas sean tan inalienables como irreductibles sin posibles intercambios culturales; b) hacia el interior de la misma cultura los derechos culturales se vuelven imperativos y coerciones culturales, que impiden las diferencias y libres identificaciones dentro de la misma cultura; la posibilidad de vivir o compartir de manera diferente la misma cultura. La educación intercultural propone además una enseñanza/aprendizaje

${ }^{11}$ En otra ocasión (cr. J. Sánchez Parga, 2005: 242-244) hemos argumentado el cuestionamiento de las cinco razones propuestas por R. Stavenhagen a favor de los derechos culturales. 
que o bien folkloriza la cultura, destacando aquellos rasgos más singulares que la diferencian de otras culturas, pero que no son necesariamente los más significantes ni entendidos en su total significación, en el sentido que significan todo el sistema cultural de dicha sociedad, o bien substantivizan y esencializan rasgos culturales, que además de no ser necesariamente exclusivos de dicha socio-cultura $o$ grupo humano no los considera histórica y sociológicamente condicionados ${ }^{12}$.

Por ello no son el intercambio, la reciprocidad y redistribución, el ideal comunitario y la interdependencia, los rasgos culturales que explican e interpretan las sociedades andinas, sino todo lo contrario: son estas las que dan cuenta de tales fenómenos culturales y es a partir de las lógicas sociales de los pueblos andinos que se comprende su cultura así como los cambios culturales. $Y$ no al contrario. Nunca la cultura explica una sociedad; es la sociedad con sus lógicas y fuerzas sociales las que explican todos sus fenómenos culturales.

Hacer, por ejemplo, de las representaciones espaciales de la temporalidad -el futuro representado en la espalda

${ }^{12}$ La minga como todas las demás instituciones del intercambio, la reciprocidad, distribución y redistribución son significantes de las culturas y sociedades andinas, ya que comparten la lógica de su organización social y de su control del espacio productivo, y hasta se expresan en la economía política de sus fiestas, de su producción del poder y de la autoridad, e incluso en la semántica de su figurativa textil. Así, la institución del intercambio como la minga en las tareas de cosecha aparece asociada a prácticas redistributivas, como el chucchir, los residuos de la cosecha recogidos por los más necesitados del grupo o comunidad. Intercambio y redistribución son incluso inherentes a la misma socialización de los niños, quienes en sus prácticas de pastoreo van recibiendo algunas crías nacidas en el rebaño bajo su cuidado. Pero estas instituciones del intercambio se encuentran siempre enmarcadas entre un umbral (mínimo) de escasez y un umbral (máximo) de acumulación, más allá de los cuales dichas instituciones serían inviables; incluso la privatización y diversificación de las estrategias productivas y económicas al interior de la comunidad vuelven contingentes las tradicionales instituciones andinas 
(washa) y el pasado de frente- una característica "propia" de las culturas andinas, es desconocer en primer lugar a qué se debe tal fenómeno y porqué se dan tales representaciones espaciales diferentes en la sociedad moderna; en segundo lugar, supone ignorar que se trata de un "rasgo cultural" propio de sociedades tradicionales, resistentes a los cambios ("sociedades frías" las llamaba Lévi-Strauss). Por eso basta que tales sociedades entren en una dinámica histórica de regulares o constantes transformaciones y se "modernicen", desarrollando, por ejemplo una "racionalidad gráfica" (Goody), para que se modifiquen no solo tales representaciones espaciales del tiempo, sino también las conductas y comportamientos temporalmente condicionados como son las disposiciones más previsoras, programadas, planificadoras y proyectivas ${ }^{13}$.

La introducción de la escritura, por ejemplo, no solo modifica la organización social del tiempo sino que además transforma la misma comunicación: "en las culturas orales los discursos de una cierta duración son siempre de tipo formulario y no analítico"14.

En conclusión, ni la cultura ni la interculturalidad son objeto de enseñanza y aprendizaje, pero en cambio la comprensión y explicación de los hechos y procesos culturales, el conocimiento de sus causas, de las razones y lógicas sociales que los producen tienen un efecto de reconocimiento, el cual además de su valor y efecto ético, y promueve un posible efecto de identificación cultural.

${ }_{13}$ Los pueblos de la Grecia homérica, anteriores a la difusión de la escritura, demostraban una mentalidad y comportamientos "pre-gráficos" también con una representación frontal del pasado, pues vivían regulados por sus tradiciones, y una representación dorsal del futuro percibido como ignoto y amenazante; igual que los pueblos tradicionales andinos.

${ }^{14}$ GOODY, J. La raison graphique. La domestication de la pensée sauvage, Edit. de Minuit, París, 1979:198). 


\section{Interculturalidad y culturalismo}

La educación intercultural no es más que un caso o problemática particular de un fenómeno más amplio y complejo, que ha hecho de la interculturalidad una suerte de programa, de ideología y hasta de valor e ideario, el cual ha sido adoptado por todo tipo de instituciones y organismos y para todo tipo de prácticas. La interculturalidad ha alcanzado hoy un rango interpelativo e imperativo análogo al que tuvo y sigue teniendo la gobernabilidad ${ }^{15}$. Un cuestionamiento crítico se impone por consiguiente ante este fenómeno. ¿Qué hay detrás o debajo de los intereses y preocupaciones por la interculturalidad?

El culturalismo. La sociedad moderna ha dado lugar a una suerte de hipertrofia culturalista con la correspondiente e inevitable atrofia de lo social, que consiste en pensar la cultura y pretender vivirla al margen de la sociedad. Como si la cultura fuera algo diferente y hasta separado de lo social. Y lo que es peor y un mayor error: se pretende comprender y explicar lo social a partir de lo cultural, cuando de hecho es siempre la sociedad y desde la sociedad que pueden entenderse e interpretarse los fenómenos culturales; los cuales poseen siempre causas sociales, respondiendo a razones y procesos sociales.

Aunque no es el caso de desarrollar aquí los factores y razones sociales, sociológicos y culturales que han producido el síndrome culturalista, dos constataciones sirven de punto de partida para una ulterior reflexión: a) el culturalismo consiste en representarse lo cultural al margen de la sociedad, no solo como dos conceptos distintos (realidades conceptualmente distintas) sino como dos realidades dife-

\footnotetext{
${ }^{15}$ No hay por ejemplo programa de desarrollo de la cooperación internacional, que no esté condicionado entre otros imperativos o "componentes transversales" (género, medioambiente...) por la interculturalidad.
} 
rentes, como si la cultura dejara de ser una cualidad de la sociedad, que la diferencia significativamente de las otras sociedades, para sustituir la misma sociedad, reduciendo esta a su cultura; b) la moderna destrucción de la sociedad societal resultado de una "producción destructiva" (Schumpeter) de un nuevo modelo de sociedad (postsocietal) acarrea una generalizada exclusión social en todo el mundo y en todas las sociedades (sociedad de exclusión) y una ruptura del vínculo social (una sociedad sin contractualidades, ni pertenencias ni interdependencias, ni seguridades...; en definitiva, una sociedad-en-redes, "network society" según Castells).

Esta profunda crisis de lo social y atrofia de socialidad podrían quedar en parte encubiertas y en parte compensadas por una hipertrofia de lo cultural; como si la pertenencia a una cultura, compartirla y participar en ella, supliera la exclusión social y la falta de participación social; como si la interculturalidad lograra encubrir y compensar la ruptura de los vínculos sociales, intercambios e interdependencias institucionales; como si la falta de una real acción social, capaz de producir sociedad y de operar las transformaciones sociales, pudiera ser compensada y suplantada por las prácticas culturales; en definitiva como si las diferencias culturales fueran capaces de encubrir y contrarrestar las profundas desigualdades sociales en todo el mundo y en cada sociedad nacional ${ }^{16}$.

Esta versión culturalista de la interculturalidad ha provocado una tenaz confusión en torno a lo que es no una acción o interacción entre culturas, sino una categoría de la misma cultura, y más exactamente la principal cualidad de la cultura, ya que las culturas solo existen interculturalmente, en referencia a otras culturas y predispuestas a los intercambios culturales.

${ }^{16}$ Para un tratamiento más amplio de esta problemática cfr. J. Sánchez Parga, Hacia una sociedad postsocietal. Transformaciones sociopolíticas del mundo global, CAAP, Quito, 2005. 
Al separar la cultura de la sociedad el culturalismo desconoce que el cambio cultural al interior de una misma sociedad o grupo humano solo puede ser explicado y comprendido en cuanto fenómeno de interculturalidad. Las transformaciones o mutaciones en la sociedad actual se han vuelto tan intensas, tan bruscas y rápidas, que las diferencias culturales coexisten simultáneamente al interior de cada sociedad. De ahí que el cambio cultural haya de ser re-conocido como interculturalidad entre los procesos más residuales de una misma cultura y sus innovaciones. Sin este reconocimiento dicho cambio cultural puede resultar tan conflictivo como traumático.

Es preciso insistir por ello, que la interculturalidad no es una práctica ni tampoco siquiera producto de una acción; la interculturalidad es el modo de existir la cultura, y por consiguiente la interculturalidad sólo puede ser objeto de reconocimiento y un re-conocimiento que genera identificaciones e identidades. Más aún, únicamente reconociendo sus internas y constantes interculturalidades puede una sociedad, pueblo o grupo humano existir culturalmente. El desconocimiento de la interculturalidad o interculturalidades a su interior hace que las sociedades y pueblos conviertan una tal ignorancia en un comportamiento tan traumático como conflictivo no solo respecto de las culturas de otros grupos y sociedades, sino incluso respecto de los propios cambios culturales. Esto mismo refuerza el planteamiento de que la cultura y la interculturalidad ni se enseñan ni aprenden, ya que una tal enseñanza-aprendizaje haría de la cultura y la interculturalidad un hecho exterior y ajeno y no tan reconocible interna como externamente.

\section{El postulado de la relatividad cultural}

La iniciativa de elaborar un sistema nacional de evaluación de la calidad de la educación intercultural bilingüe 
en Ecuador ha sido cuestionada y quedado bloqueado su tratamiento, al objetarse que la misma "idea de calidad educativa es cultural", y por consiguiente relativa a cada una de las culturas o grupos indígenas, que participan de dicho programa nacional de educación ${ }^{17}$. Este relativismo cultural pone actualmente en riesgo la misma administración de la educación intercultural bilingüe en el país, pues ya han surgido iniciativas de algunos grupos indígenas para institucionalizar su propia dirección nacional para la educación intercultural bilingüe en su propia lengua y cultura.

Este no sería más que uno de los muchos e ilimitados casos, que hacen de la cultura un principio no demostrado ni demostrable de relativismo ${ }^{18}$. Con el agravante de que el relativismo cultural se impone más por razones éticomorales o de "political correctness" que por razones teóricas. Siempre ha sido un comportamiento habitual pero espontáneo el recurrir a la cultura y a lo cultural, para relativizar hechos históricos y sociales, como si fuera la cultura y la "razón cultural", la que puede explicar o dar cuenta de estos, cuando en realidad es siempre y necesariamente lo contrario: los hechos culturales son siempre históricos y sociológicos, y por ello mismo únicamente pueden ser comprendidos y explicados sociológicamente y en razón de procesos históricos; siendo siempre los cambios sociales los que provocan y explican los cambios culturales.

En otras palabras, la cultura es una categoría de la sociedad, y por consiguiente solo desde la sociedad puede

${ }^{17}$ Cfr. GARCÉS, Fernando. Situación de la educación intercultural bilingüe en Ecuador, Documento encargado por el PROEIB Andes y el Banco Mundial, y procurado por Sebastián Granda, 2004. Sobre el carácter cultural de la calidad educativa el autor cita a A. Moya, 2003:37 y Abram, 2004:11.

${ }^{18}$ Para la clásica Gnoseología crítica como para la teoría del conocimiento no hay doctrina más fácilmente cuestionable que el relativismo en cualquier de sus formas. El relativismo cultural se remonta a Dilthey (1833-1911), padre del historicismo moderno, cuyas obras fundamentales presentan una elocuente convergencia: Crítica de la razón histórica y ciencias de la cultura. 
ser pensada: ya sea en cuanto diferencias culturales al interior de la misma sociedad, ya sea en cuanto diferencias significantes respecto de otras sociedades y culturas; pero también en cuanto área cultural compartida por otras diferentes sociedades.

El relativismo cultural corre el riesgo extremo de incurrir en una ideología del resentimiento, la cual comporta un doble error, por lo demás muy paradójico: por un lado es incapaz de reconocer las específicas diferencias significantes de una cultura, considerando que tales diferencias pueden ser generalizadas a otras socio-ecultural, y por otro lado se resiste a reconocer que las innovaciones y originalidades culturales de una sociedad puedan ser objeto de difusión y de apropiación por parte de otras sociedades y culturas. En ambos casos un tal relativismo cultural reforzado de un resentimiento ideológico, se incapacita para toda posible interculturalidad y por consiguiente para cualquier real identificación cultural. De un lado, por ejemplo, considera filosófica o científica cualquier forma de pensamiento o de producción de saberes y conocimientos, ignorando o desconociendo así las especificidades propias no solo del pensamiento filosófico y del conocimiento científico sino también las especificidades propias de las otras formas de pensar y conocer; y de otro lado, por ejemplo, considera que sociedades con un pasado cultural particular no pueden adoptar o utilizar aquellas producciones culturales originarias de otras sociedades, pero que el proceso histórico y civilizatorio han difundido y universalizado: la escritura, el cálculo matemático o el análisis lingüístico ${ }^{19}$.

Otro de los errores en los que incurre la educación intercultural, producto también del culturalismo, consiste en

\footnotetext{
${ }^{19}$ Sin negar el fenómeno de la difusión cultural a lo largo de la historia, la teoría del difusionismo pretende explicar todos los parecidos y similitudes culturales entre sociedades por efecto de difusión, ignorando factores históricos y sociológicos. Por ejemplo, los tabúes de la caza en todos los continentes.
} 
agregar al relativismo postmodernista y a la introducción masiva de la opiniones como si fueran ideas y conocimientos en las CCSS (cuando aquellas a diferencia de estos no requieren ser explicadas y justificadas), una modalidad de relativismo muy extendida, que cuestiona la verdad o cientificidad de tradiciones teóricas y conceptuales, por el simple hecho de haber sido relativas a una cultura particular, y que por consiguiente no podrían ser trasladadas y menos impuestas a otros pueblos o sociedades diferentes ${ }^{20}$. Esto supondría que los hechos culturales originarios de una sociedad serían incompatibles con otras sociedades y pueblos, cuando el desarrollo civilizatorio a lo largo de la historia ha demostrado todo lo contrario: hechos culturales originados en una cultura no solo han podido difundirse en el resto de culturas del mundo, sino que son precisamente los hechos culturales los que más y con mayor rapidez se difunden entre las más diferentes sociedades ${ }^{21}$. Tales presupuestos se encuentran históricamente contradichos por un principio fundamental: las sociedades humanas lejos de ser impermeables o reacias a todo intercambio y difusión culturales, se hallan más bien abiertas y predispuestas a la aculturación ${ }^{22}$.

${ }^{20}$ Sería tan insostenible negar el valor y utilidad de la escritura por haber nacido hace cinco mil años en tres distintas áreas culturales (del Nilo, Mesopotamia y el Indo), como negar el valor y validez del análisis estructural o de las teorías lingüísticas, por haber sido elaboradas desde una determinada región cultural e intelectual.

${ }^{21}$ El relativismo postmoderno es feudatario de una suerte de democratismo ideológico, según el cual cualquier idea valdría tanto como cualquier otra, ya que todas participan de la misma igualdad de derecho de toda democracia, lo que implica extender la democracia, en cuanto regímen político y de gobierno a todos los demás ámbitos de la sociedad. De ahí también la moda actual de consensuar las ideas y los conocimientos, o los programas académicos de una carrera universitaria, como si el criterio de verdad, de certeza o de coherencia científica y académica se decidieran por un régimen de acuerdos de mayorías o minorías.

${ }^{22}$ Esto no excluye el caso de reacciones frente a determinados procesos de "aculturación", que podrían tener efectos destructores en la sociedad. 
De manera opuesta, otra variación del culturalismo, muy asociada al relativismo cultural, y que se encuentra presente en programas de educación intercultural, consiste en generalizar a todas las culturas lo que apareció y se desarrolló como característica de una cultura particular y de un particular desarrollo cultural. La filosofía, por ejemplo, ha significado una forma muy particular de pensamiento, de elaborar y organizar los conocimientos, y que además se ha desarrollado de acuerdo a una también determinada tradición intelectual; sin embargo, se pretende llamar también filosofía a otras formas de pensar, que han tenido lugar en la historia y en otros pueblos o sociedades al margen de tales características específicas propias del pensamiento filosófico. En este sentido hablar de la "filosofía egipcia" o de la "filosofía romana" o de la "filosofía andina" implica tanto desconocer la especificidad del pensamiento filosófico como la especificidad de las otras particulares formas de pensar $^{23}$.

Algo muy similar ha ocurrido con la ciencia y con la medicina, considerada esta como un particular sistema de salud, que tuvo una forma muy determinada de constituirse y organizarse y que además alcanzó una desarrollo histórico también muy particular (fundado en los principios científicos de la observación y experimentación) y que siempre se caracterizó por rasgos muy específicos (somático, anatómico y progresivamente especializado, muy basado en la medicación y en la cirugía). Que el sistema de salud médico se halla impuesto sobre otros sistemas de salud, no jus-

${ }^{23}$ Que hubo un pensamiento español y un pensamiento italiano, e incluso reconocer la existencia de filósofos en ambos países no justificaría hablar de una filosofía española o italiana, sino en términos muy analógicos respecto de lo que fue una filosofía medieval o una filosofía alemana y francesa. E incluso reconocer que el existencialismo fue un movimiento filosófico europeo con manifestaciones en diferentes pensamientos nacionales, impediría reconocer, por ejemplo, que hubo un pensamiento existencialista británico. 
tifica que estos hayan de ser asimilados a aquel, ya que se confundirían las especificidades propias de cada uno y que los diferencian entre sí.

\section{Ética política de una antropología de la cultura}

En lugar de abordar el problema de la cultura y de la interculturalidad desde la educación, sería más bien necesario precisar el problema antropológico de fondo y redefinir su tratamiento en términos ético-políticos.

Es evidente que tanto en sus intenciones y objetivos, como en sus objetos y contenidos la educación intercultural y su enseñanza-aprendizaje de la cultura son más retóricos y doctrinales, que productores y transmisores de conocimientos. La educación intercultural se ha dotado de unas finalidades y metas demasiado instrumentales y no tantas transformadoras a través del conocimiento. Como se señalaba más arriba, mientras que los conocimientos sobre cultura no comporten una comprensión de los hechos culturales, nunca darán lugar a re-conocimientos, ni tampoco harían posibles las identificaciones culturales.

Por esta razón se concibe la interculturalidad en términos tan operativos, como si se tratara de la acción entre culturas, de su interacción entre ellas, ignorando así cuatro hechos fundamentales: a) que la interculturalidad es una categoría de la cultura, una forma de existir todas las culturas, y por consiguiente supone el reconocimiento del "otro", de las diferencias culturales y de la misma interculturalidad existentes al interior de cada cultura, por más original y originaria que sea; b) que sin tal reconocimiento de las propias interculturalidades internas, ninguna cultura estaría en condiciones de reconocer y reconocerse e identificarse con otra cultura diferente, para llegar a establecer con ella un efectivo intercambio cultural; c) que no son las culturas sino las sociedades las que entran en relación, y que cualquiera que 
sean las relaciones entre sociedades, siempre tienen efectos de interculturalidad; d) por consiguiente, la intercultualidad es ante todo y sobre todo el reconocimiento e identificación con "otra" cultura, pero siempre al interior de relaciones e interacciones entre sociedades, pueblos, grupos humanos o clases y sectores sociales con sus consiguientes efectos de interculturalidad.

Enseñar la cultura para reforzar una supuesta identidad cultural, tendrá siempre el enorme riesgo de generar un des-re-conomiento no solo respecto de la otra cultura, sino incluso -y lo que sería peor- respecto de los procesos de cambio cultural al interior de la misma sociedad o grupo humano. Este fenómeno de múltiple des-re-conocimiento pudo ser observado en una investigación reciente en una zona de comunidades indígenas precisamente cubierta desde hace casi dos décadas por programas de educación intercultural bilingüe con esta orientación ${ }^{24}$. En estas comunidades se des-re-conoce a los jóvenes migrantes (migrantes desde la edad de 7 y 14 años) porque regresan a sus comunas con zapatos reebock, vestidos de raperos y con músicas heavy metal; estos mismos jóvenes se han hecho una imagen de mujer en la costa y en la ciudad, que les lleva a des-re-conocer a sus propias jóvenes mujeres, las cuales a su vez, des-re-conociéndose en su propia imagen y en sus tradiciones culturales, huirán de sus comunidades para buscar una imagen femenina en la que ellas mismas reconocerse y poder ser reconocidas. Se diría que basta un fenómeno de des-re-conocimento, para que este desencadene otros múltiples des-re-conocimientos en serie. Lo que permitiría suponer que también bastaría un fenómeno de reconocimiento a partir de un proceso educativo con otras

${ }^{24}$ Cfr. SÁNCHEZ PARGA, José. Crisis en torno al Quilotoa. Mujer, comnidad y cultural, CAAP, Quito, 2002. 
orientaciones y contenidos, para que pudiera desencadenarse un proceso de reconocimientos culturales en serie.

Este mismo fenómeno demostraría que solo los reconocimientos de las diferencias culturales al interno de una comunidad o sociedad son los que hacen posible los reconocimientos culturales entre sociedades y grupos humanos.

Si lo que se pretende con el programa y educación interculturales es mejorar las relaciones e intercambios entre sociedades, sería necesario despejar el enorme error de pensar que son las culturas las que luchan entre ellas y que el "enfrentamiento entre culturas" y civilizaciones (el supuesto clash of civilizations de Huntington) sería la explicación de esa suerte de guerra global entre etnias y culturas, que actualmente parece extenderse por todo el mundo.

De ese imponente malentendido de las luchas y conflictos interculturales es preciso destacar de nuevo dos falsos presupuesto, resultantes de lo que entendemos por culturalismo: a) las culturas no son realidades diferentes y autónomas de las sociedades y los pueblos, y mucho menos existen y actúan al margen de ellos; b) nunca son las culturas sino las sociedades, pueblos y grupos humanos o clases sociales los que luchan y se enfrentan entre sí, los que dominan unos a otros. En este sentido lo que aparece como luchas étnicas y entre culturas -o entre religiones- no son más que un encubrimiento de las reales guerras entre fuerzas e intereses políticos y económicos.

Una primera consecuencia de este planteamiento es que si son más bien los poderes e intereses económicos y políticos los que siempre luchan entre sí y se enfrentan en guerras, las culturas aparecen entonces como el ámbito privilegiado y excepcional, donde es posible el pacificar tales guerras y atenuar dichos conflictos. Sería más bien "el pacto de civilizaciones" o la participación en "áreas culturales", en procesos de cultura compartidos, el único programa 
que garantizaría y caracterizaría una "paz estable" (Kant) en el mundo actual.

Según esto, la inteculturalidad en vez de quedar reducida a un programa educativo de carácter retórico y doctrinario, sin ninguna garantía de eficacia, solo aparece posible y eficiente en cuanto una teoría de la cultura y una práctica del reconocimiento e identificación con el otro (cultural). Puesto que únicamente cuando se conocen y comprenden las causas y razones de los fenómenos y procesos culturales es posible intervenir en estos tanto como en aquellos. Considerando que el reconocimiento no es solamente una disposición cognoscitiva sino sobre todo una práctica ética. Reconocer que la otra cultura, precisamente en lo que la diferencia, tiene sentido para mi propia cultura, significa reconocerse en ella. Es por consiguiente la misma cultura, y su precisa dinámica intercultural, lo que se manifiesta como programa ético de la sociedad moderna en un mundo global. Solo la razón cultural podría resolver todas las luchas y conflictividades y en particular aquellas que precisamente aparecen como étnicas y culturales. 
